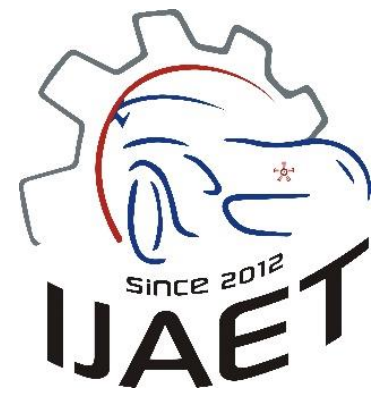

e-ISSN: 2146 - 9067

International Journal of Automotive

Engineering and Technologies

journal homepage:

https://dergipark.org.tr/en/pub/ijaet

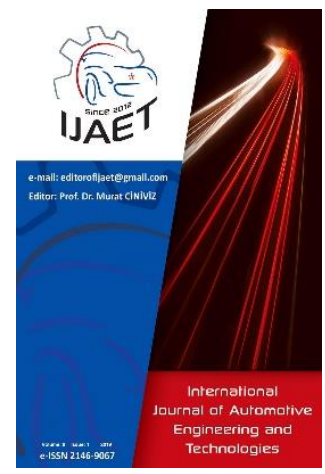

Original Research Article

\title{
Impact of various lambda values on engine performance, combustion and emissions of a SI engine fueled with methanol- gasoline blends at full engine load
}

\author{
Selçuk Sarıkoç ${ }^{1, *}$ \\ 1 * Tasova Vocational School, Amasya University, Amasya, Turkey
}

\section{ARTICLE INFO}

$10000-0003-1190-5238$

* Corresponding author sarikocselcuk@gmail.com

Doi: $10.18245 /$ ijaet. 735553

Received: May 11, 2020 Accepted: Nov 17, 2020

Published by Editorial Board Members of IJAET

(C) This article is distributed by Turk Journal Park System under the CC 4.0 terms and conditions.

\begin{abstract}
The aim of this study is to investigate experimentally the effects of methanolgasoline fuel blend on engine performance, combustion process, and exhaust emissions of a spark ignition (SI) engine under various lambda values at full engine load. Firstly, the methanol was blended with gasoline by volume fraction of $20 \%$, which renamed as M20. The experiments were performed a constant engine speed at $2000 \mathrm{rpm}$ and full load conditions. Then, the M20 fuel blend effects on the engine performance, combustion and exhaust emission characteristics were compared with pure gasoline fuel in terms of brake engine torque, brake specific fuel consumption (BSFC), thermal efficiency, combustion process, $\mathrm{CO}, \mathrm{CO}_{2}, \mathrm{HC}$ and $\mathrm{NO}$ emissions at three different lambda values such as $0.8,1,1.2$. It was found that the addition of methanol substantially affected the engine performance, combustion process, and exhaust emissions at various lambda values. The methanol properties such as higher oxygen content, octane number, laminar flame speed (LFS), latent heat vaporization, and lower calorific value, and also the variation of the air-fuel ratio of the test fuels substantially influenced on the test results. Furthermore, these properties considerably affected the combustion characteristics such as ignition delay (ID), and combustion duration (CD). According to obtained results, the highest engine performance was observed for gasoline at $\lambda=1$. The M20 test fuel was exhibited a better combustion process when at $\lambda=0.8$ among other lambdas compared to gasoline. However, the best emission performance was obtained at $\lambda=1$ for the M20. Thus, the M20 test fuel can be used as a fuel considering the combustion and exhaust emissions. Overall, the engine performance, combustion, and exhaust emission characteristics are considerably affected by the variety of air-fuel ratio, oxygen content, octane number, LFS, and latent heat vaporization properties.
\end{abstract}

Keywords: Methanol-gasoline blend, various lambda, engine performance, combustion, emission

\section{Introduction}

In this century, biofuels are attracting attention due to environmental problems, energy security concerns, decrease the current deficit, and socioeconomic reasons. Generally, lower exhaust emissions are emitted by biofuels such as biomethanol, biodiesel, bioethanol, and biohydrogen to compared fossil-based fuels [1, 2]. Therefore, researchers have shown an increased interest in alternative fuels nowadays 
due to they are one of the most promising fuel additives in the future [3]. Thus, alternative fuels such as bio-oils and bio-alcohols can be produced from forest waste for using in the internal combustion engine [4]. In this respect, alternative biofuels have been studied by many researchers using in the internal combustion engine such as methanol [5], bioethanol [6], and biodiesel [7]. Thus, a considerable amount of study in the literature has been published about using alternative biofuels in the internal combustion engine. Balki and Sayın [8], investigated pure ethanol and methanol the effects on engine performance, combustion, and emission characteristics under various compression ratios. They reported that usually the engine performance and combustion were increased, while the exhaust emissions were decreased by the use of pure ethanol and methanol compared to gasoline at under all different compression ratios. Sarıkoç et al. [9], reported that the addition of methanol increased the thermal efficiency, the BSFC, maximum cylinder pressure, and heat release rate at stoichiometric lambda. Besides, the exhaust emissions positively affected by the methanol blends, except NO emissions. Danaiah et al. [5] studied the addition of methanol in the gasoline in the volumetric ratio of $5 \%, 10 \%$, and $15 \%$, respectively. They investigated the effect of methanol rate on engine performance and exhaust emissions. The higher brake thermal efficiency is achieved by $10 \%$ of the methanol blend, while the lower emissions are observed when $15 \%$ of the methanol rate compared to the other blends. Furthermore, Agarwal and Dhar [10] concluded that the M20 fuel blend was higher brake thermal efficiency than M10 test fuel.

According to reachable literature, a great number of the researchers have investigated the effects of different fuel blend ratios on the engine performance, combustion process, and emission characteristics of a SI engine. A few experiments have been performed to discover the effects of methanol-gasoline fuel blend on engine performance, combustion process, and exhaust emissions of a SI engine. However, researchers have not comprehensively investigated the effects of methanol-gasoline blends on the engine performance, combustion, and emission characteristics of a SI engine under various lambda values at full engine load. Thus, the objective of this investigation is to clarify the effects of various lambda and full engine load values on the engine performance, combustion and emission characteristics of a SI engine fueled with methanol-gasoline blends were comprehensively investigated.

Table 1. The properties of the test engine

\begin{tabular}{lc}
\hline Brand and Model & Ford MVH418 \\
\hline Engine type & Four-stroke, Spark Ignition \\
Number of Cylinders & 4 \\
Cylinder volume, $\mathrm{cm}^{3}$ & 1796 \\
Bore-Stroke, mm - mm & $80.6-88$ \\
Compression ratio & $10: 1$ \\
Max. engine speed, rpm & 5950 \\
Max. engine torque, Nm & $153(4000 \mathrm{rpm})$ \\
Max. engine power, $\mathrm{kW}$ & 77 \\
Cooling system & Water-cooled \\
Fuel system & Multi-port fuel \\
\hline
\end{tabular}

\section{Materials and Methods}

\subsection{Experimental setup and procedure}

The engine tests were conducted in the Engine Laboratory of the Mechanical Engineering Department at Erciyes University. The engine speed was chosen as $2000 \mathrm{rpm}$ due to the average maximum performance obtained in this value [11]. In another study, the engine tests were performed at $2000 \mathrm{rpm}$ with the same engine [12]. Therefore, the tests were performed with pure gasoline, and methanol-gasoline fuel blend at full engine load and $2000 \mathrm{rpm}$ constant engine speed. Three different lambda values $(0.8,1,1.2)$ effects were investigated in terms of engine power, the BSFC, the thermal efficiency, and exhaust emissions ( $\mathrm{CO}, \mathrm{CO}_{2}$, and $\mathrm{NO}$ ) under these specific engine conditions. The airflow rate was controlled to obtain that the lambda values provided at $0.8,1$, and 1.2, respectively. Meanwhile, the throttle valve position was manually set according to each test fuel to obtain constant lambda and full engine load values when changing the air-fuel rate.

A Ford brand, MHV418 model, $1.756 \mathrm{~L}, 77 \mathrm{~kW}$, four-cylinder, four-stroke, naturally aspirated a SI direct-injection gasoline engine was used in the experiments. Table 1 presents an overview of the engine specifications. An eddy-current type dynamometer was coupled with the engine for measuring the engine torque and speed. Cylinder pressure was measured by a PCB 


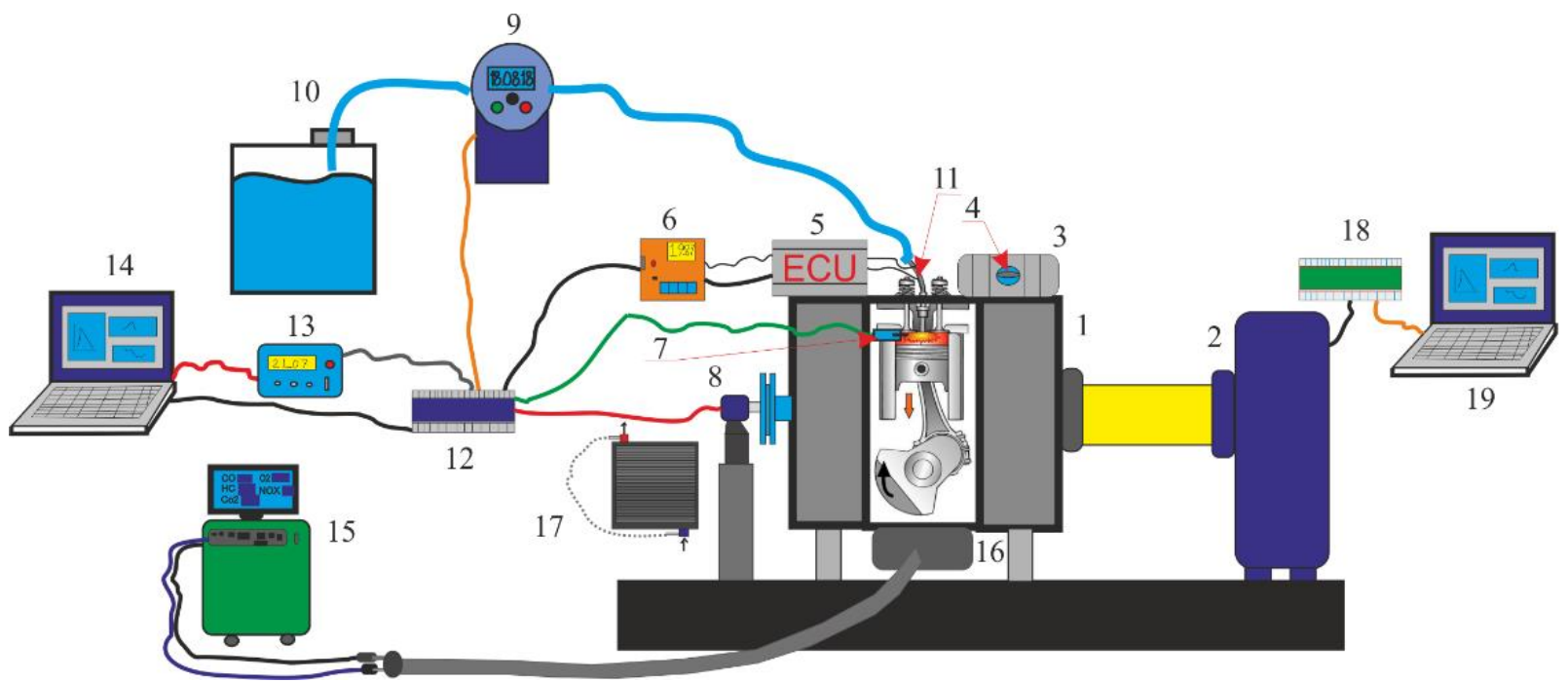

The number presents the engine components, respectively: 1. Spark-ignition engine, 2. Eddy-current dynamometer, 3. Intake manifold, 4. Intake throttle valve, 5. ECU, 6. Advanced ignition unit, 7. Cylinder pressure sensor, 9. Fuel flowmeter, 10. Fuel tank, 11. Fuel injector, 12. Data acquisition card, 13. Amplifier, 14. Combustion analyzer, 15. Exhaust gas analyzer, 16. Exhaust manifold, 17. Radiator, 18. Dynamometer data acquisition card, 19. Dynamometer control panel.

Figure 1. The engine setup and components

113B22 piezoelectric pressure sensor. A Krohne OptiMass 3000 liquid mass flow meter was used for measuring fuel consumption. A Bosch brand BEA 60 model emission gas analyzer was used for detecting the $\mathrm{CO}, \mathrm{CO}_{2}, \mathrm{O}_{2}, \mathrm{HC}$, and $\mathrm{NO}$ exhaust emissions. Table 2 provides the technical properties of the gas analyzer.

The engine setup and components are shown in the experimental system details in Fig. 1. The most important properties of the methanol and gasoline are presented in Table 3.

Table 2. Gas analyzer technical properties.

\begin{tabular}{ccc}
\hline Gases & Measure range & Sensitivity \\
\hline $\mathrm{CO}_{2}, \% \mathrm{v} / \mathrm{v}$ & $0-18 \% \mathrm{vol}$ & $0.01 \% \mathrm{vol}$ \\
$\mathrm{CO}, \% \mathrm{v} / \mathrm{v}$ & $0-10 \% \mathrm{vol}$ & $0.001 \% \mathrm{vol}$ \\
$\mathrm{O}_{2}, \% \mathrm{v} / \mathrm{v}$ & $0-22 \% \mathrm{vol}$ & $0.01 \% \mathrm{vol}$ \\
$\mathrm{HC}, \mathrm{ppm}$ & $0-9999$ & $1 \mathrm{ppm}$ \\
$\mathrm{NO}, \mathrm{ppm}$ & $0-5000 \mathrm{ppm}$ & $1 \mathrm{ppm}$ \\
Lambda & $0.5-1.8$ & $0.1 \%$ \\
\hline
\end{tabular}

Table 3. The properties of the test fuels [13,14].

\begin{tabular}{lcc}
\hline \multicolumn{1}{c}{ Fuel properties } & Gasoli & Methanol \\
\hline Chemical Formula & $\mathrm{C}_{8} \mathrm{H}$ & $\mathrm{CH}_{3} \mathrm{OH}$ \\
Density $\left(\mathrm{kg} / \mathrm{m}^{3}\right)$ & 715 & 792 \\
LHV $(\mathrm{MJ} / \mathrm{kg})$ & 43 & 20.05 \\
Octane Number & 92 & 111 \\
Oxygen Content $(\%)$ & - & 50 \\
Latent Heat $(\mathrm{kJ} / \mathrm{kg})$ & 307 & 1147 \\
LFS $(\mathrm{cm} / \mathrm{s})$ & $33-$ & 52 \\
\hline
\end{tabular}

\subsection{Error analysis of the engine test system}

Kline and McClintock [15] presented a highly precise method that estimating the uncertainty of experimental results. In this respect, this method was implemented to the engine system results for the purpose of determining the error analysis of the engine test system as follows:

$$
\begin{gathered}
w_{R}=\left[\left(\frac{\partial R}{\partial x_{1}} w_{1}\right)^{2}+\left(\frac{\partial R}{\partial x_{2}} w_{2}\right)^{2}+\cdots\right. \\
\left.+\left(\frac{\partial R}{\partial x_{n}} w_{n}\right)^{2}\right]^{\frac{1}{2}}
\end{gathered}
$$

$\mathrm{x}_{1}, \mathrm{x}_{2}, \mathrm{x}_{3}, \ldots, \mathrm{x}_{\mathrm{n}}$ and $\mathrm{w}_{1}, \mathrm{w}_{2}, \ldots, \mathrm{w}_{\mathrm{n}}$ are independent variables and uncertainties of the independent variables, respectively, that a given $\mathrm{R}$ function. Where $w_{R}$ is the total percentage error value of the engine test system.

\section{Results and Discussion}

The results of the study have been divided into four subjects which are dealing with error analysis, engine performance, combustion characteristics, and exhaust emissions, respectively.

\subsection{The error analysis}

The error analysis was calculated by using the formulas described by Ref. [16]. The engine system error parameters such as the engine power, torque, fuel consumption, thermal efficiency, emission were calculated to be $0.244,1.162,2.568,0.002$, and 0.001, respectively. It is obvious that the calculated error ranges from 0.001 to $2.568 \%$ of the parameters. According to the results, the total 
system error limit calculated to be $\pm 2.829 \%$ rate which is lower than $\pm 5 \%$. This value is a good agreement with the limit of the engineering error rate [17]. The details of the system components' accuracy value and calculated error values of each parameter are given in Table 4.

Table 4. The accuracy and calculated error values of each parameter of the system components.

\begin{tabular}{|c|c|c|c|c|}
\hline \multicolumn{2}{|c|}{ Test Equipment } & Accuracy & $\begin{array}{l}\text { Calculated } \\
\text { results }\end{array}$ & $\begin{array}{l}\text { Error } \\
(\%)\end{array}$ \\
\hline \multirow{3}{*}{\multicolumn{2}{|c|}{$\begin{array}{l}\text { Eddy-Current } \\
\text { Dynamometer } \\
\text { Pressure Sensor } \\
\text { Digital Rotary } \\
\text { Encoder }\end{array}$}} & $\pm 0.25 \%$ & Brake Torque & 0.244 \\
\hline & & $\pm 1 \%$ & Brake Power & 1.162 \\
\hline & & $\pm 0.01 \mathrm{rpm}$ & BSFC & 2.568 \\
\hline \multicolumn{2}{|c|}{$\begin{array}{l}\text { Fuel mass flow } \\
\text { meter }\end{array}$} & $\pm 0.1 \%$ & $\begin{array}{l}\text { Brake } \\
\text { Thermal } \\
\text { Efficiency }\end{array}$ & 0.002 \\
\hline \multirow{5}{*}{$\begin{array}{l}\text { Exhaust } \\
\text { Gas } \\
\text { Analyzer }\end{array}$} & $\mathrm{CO}_{2}$ & 0.01 vol. $\%$ & Emission & 0.001 \\
\hline & $\mathrm{CO}$ & 0.001 vol. $\%$ & Total System & 2.829 \\
\hline & $\mathrm{HC}$ & $1 \mathrm{ppm}$ & & \\
\hline & $\mathrm{NO}$ & $1 \mathrm{ppm}$ & & \\
\hline & $\mathrm{O}_{2}$ & 0.1 vol. $\%$ & & \\
\hline
\end{tabular}

\subsection{The engine performance}

The engine performance characteristic for methanol-gasoline blends was compared with various lambda values at full load engine condition, as given in Fig. 2 and Fig. 3, respectively. The thermal efficiency is a measure of how much chemical energy in fuel can transfer to mechanical energy [14]. Thus, the thermal efficiency decreased with the reduction of lambda values due to the efficiency strongly depended on the input mass of the fuel. Therefore, the efficiency increased with the increase of the lambda values for the test fuels. It is calculated that the value of lambda $0.8,1$, and 1.2 efficiencies have $27.24 \%, 33.60 \%$, and $36.33 \%$ for G100, while $27.67 \%, 34.71 \%$, and 35.97 for M20, respectively. According to the results, it is obvious that the highest thermal efficiency values obtained at 1.2 lambda value. In this respect, the maximum thermal efficiency was measured $36.33 \%$ for G100 test fuel at 1.2 lambda value and full load engine condition. However, M20 exhibited the efficiency of $35.97 \%$. It is obvious that the addition of the methanol the thermal efficiency value to be $0.99 \%$ less than gasoline at 1.2 lambda value. Although the methanol $(20.05 \mathrm{MJ} / \mathrm{kg})$ has approximately half the lower heating value compared to gasoline (43 $\mathrm{MJ} / \mathrm{kg})$ [13], the addition of methanol has increased the efficiencies up to $1.55 \%$ and $3.31 \%$ compared to G100 at 0.8 and 1 lambda values, respectively. This situation can be explained with excess air slightly affected the combustion efficiency of the M20 blend at 1.2 lambda value. However, the efficiency can be apparently increased by the methanol addition at a rich and stoichiometric air-fuel zone. Methanol slightly decreased the thermal efficiency value to be $0.99 \%$ less than gasoline at 1.2 lambda value. This situation can be explained with alcohols have a higher octane number, charge cooling ability, and rich oxygen content of fuel characteristics $[13,18]$ that lead to better combustion and engine stability so the M20 blend caused more thermal-efficient than gasoline, except the leaner air-fuel zone at 1.2 lambda value. Nevertheless, the thermal efficiencies have exhibited an increasing trend with the increase of lambda values. This result is in agreement with Li et al study [14], which reported that the brake thermal efficiency increased with a reduction of equivalence ratio that has a reciprocal relation with lambda value. Balki and Sayin [8] reported that the maximum combustion efficiency achieved with pure methanol was $99.45 \%$, whereas pure gasoline was $97.57 \%$ at the compression ratio of 8.5:1. Galloni et al. [19] declared that the increase of $\mathrm{CO}$ emissions decreased the thermal efficiency of the engine due to the lack of enough $\mathrm{O}_{2}$ amounts. The $\mathrm{CO}$ reaction leads to the rich fuel mixture is not fully converted to $\mathrm{CO}_{2}$ during the combustion process. Thus, an important amount of energy is released into the atmosphere by means of $\mathrm{CO}$ emission. In this respect, the addition of the methanol increased the oxygen rate of the fuel blend. Therefore, the $\mathrm{CO}$ emission values decreased to be $1.55 \%$ and $54.26 \%$ at $\lambda=0.8$ and $\lambda=1$, respectively. In addition to these, Zhang et al. [18] explained that the octane number and charge cooling effect of fuels substantially affect the anti-knock ability. Furthermore, Çelik et al. [20] determined that the engine thermal efficiency is considerably improved by the high antiknocking resistance of the pure methanol at the same compression ratio compared to gasoline. Thus, a positive effect on the thermal efficiency of the engine is obtained by the addition of methanol which leads to the regular working of the engine. Considering overall, this increase in 
thermal efficiency is not only resulted from improving the combustion efficiency, but also the engine performance, exhaust emissions, and fuel properties effects.

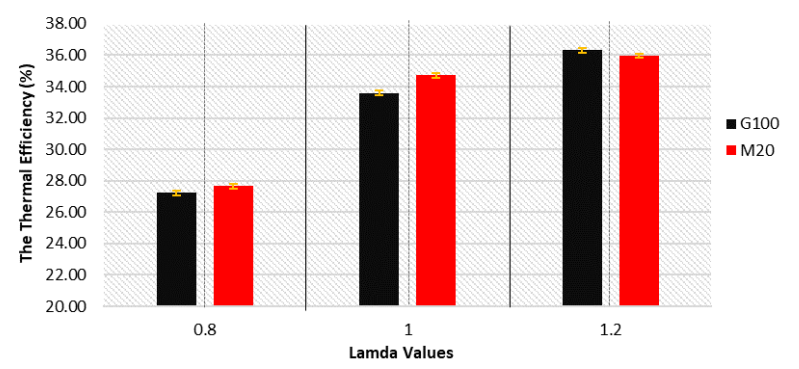

Figure 2. The thermal efficiency values compared to lambda values.

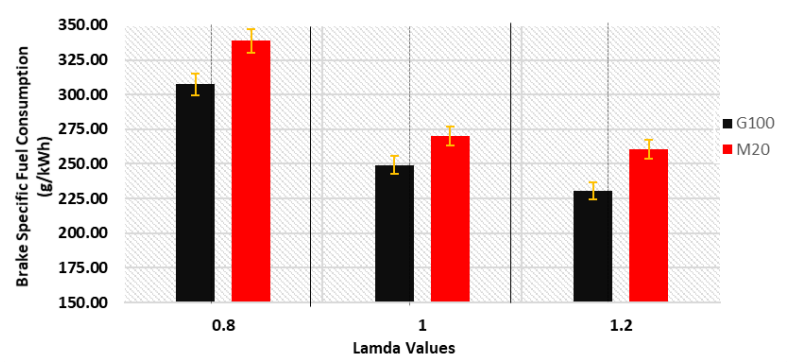

Figure 3. BSFC values compared to lambda values.

The profile of BSFC against lambda values under full load is given in Fig. 3. With increasing lambda values, the BSFC values were decreased for all test fuels. According to results in Fig. 3, $\lambda=1.2$ exhibited the lowest BSFC in the lambda values. However, it is apparent from this figure, the addition of methanol considerably increased the BSFC values. Furthermore, it can be concluded that $0.8,1$ and 1.2 lambda values have $10.24 \%$, $8.37 \%$ and $13.06 \%$ rates higher BSFC than gasoline. As can be seen, the maximum increase was $338.78 \mathrm{~g} / \mathrm{kWh}$ at $\lambda=0.8$ when methanol was added. The results, as shown in Fig. 3, indicate that the BSFC values are increased by the addition of methanol in gasoline due to the BSFC substantially depends on the LHV of test fuels. This result is in a good agreement with in the previous study, which reported that a strong relationship between the BSFC and LHV of fuels [14]. However, the LHV of methanol has not considerably affected the engine torque values compared to G100. These changes were observed by an increase of $0.34 \%$ and $0.26 \%$ at 0.8 and 1 lambda values, while a decrease of $0.39 \%$ at 1.2 . The engine torque variations are presented in Fig. 4. Overall, the obtained results revealed that the addition of methanol into gasoline causes an increase in the BSFC at all lambda values.

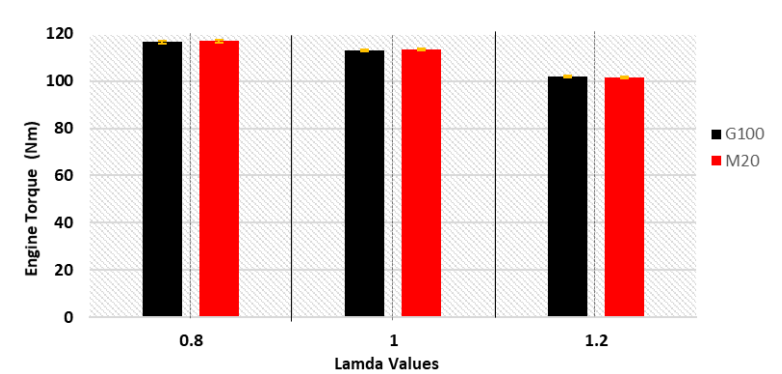

Figure 4 . The engine torque values compared to lambda values.

\subsection{The combustion characteristic}

The combustion characteristics of the test fuels under various engine conditions were addressed by measuring the combustion chamber pressure and these data were used for calculating the heat release rate of the engine. Extensive evaluations have been reported about the combustion characteristics of each test fuels under various lambda values. In this respect, cylinder pressure and net heat release rate of methanol-gasoline blend under various lambda values were compared with each other, as given in Fig. 5. It is obvious that the combustion characteristic was considerably affected by the addition of methanol and the changing of the lambda values.

A number of researchers have reported that the ignition delay expressed by $0-10 \%$ mass fraction burned (MFB) and the combustion process 1090\% MFB [14,21]. Thus, the combustion phasing can be calculated for different test fuels and engine conditions to evaluate further analysis [14]. As seen in Table 5, the ID and CD values increased with the rising of the lambda values for both test fuels. However, the addition of methanol in gasoline fuel led to a reduction in the ID period. On the other hand, the methanol increased the $\mathrm{CD}$ period compared to gasoline. It is obvious that the methanol considerably affects the ID and CD period. This situation can be explained by several possible reasons. It is almost certain that the fuel properties are a result of these effects. There is a strong possibility that one of the most important reasons can be the higher LFS, heat evaporation and octane number of the methanol. These findings agree with the results of other studies.

A number of researchers have reported that the ignition delay expressed by $0-10 \%$ mass fraction burned (MFB) and the combustion process 1090\% MFB [14,21]. Thus, the combustion phasing can be calculated for different test fuels 


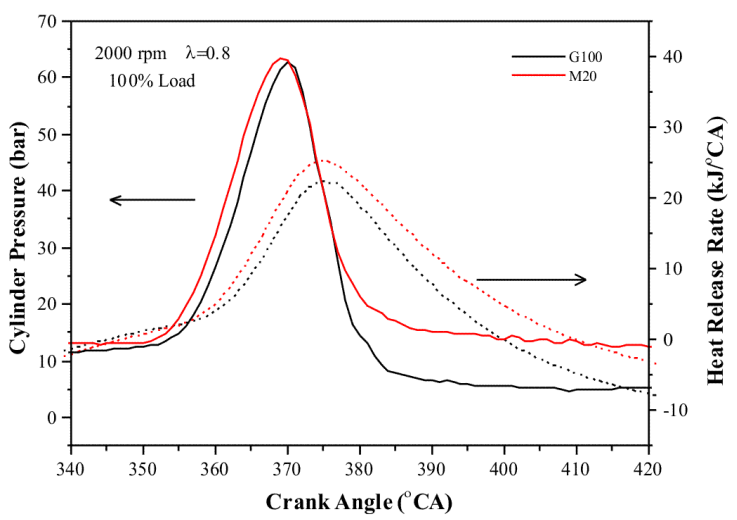

a

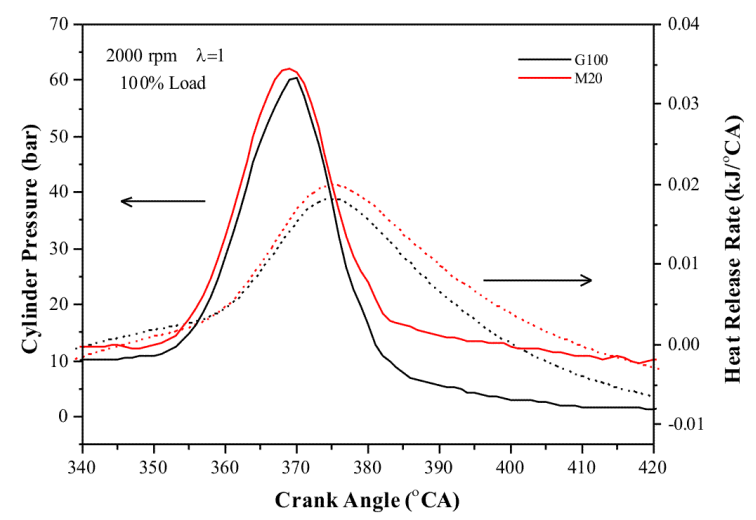

b

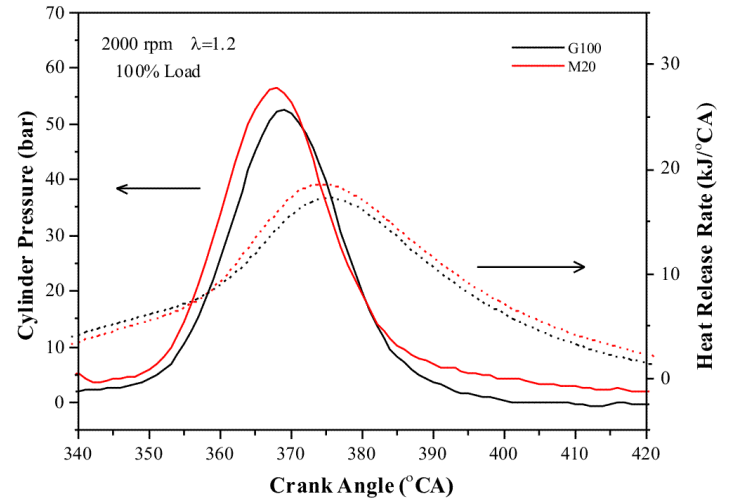

Figure 5. The combustion process of test fuels at various lambda values

and engine conditions to evaluate further analysis [14]. As seen in Table 5, the ID and CD values increased with the rising of the lambda values for both test fuels. However, the addition of methanol in gasoline fuel led to a reduction in the ID period. On the other hand, the methanol increased the $\mathrm{CD}$ period compared to gasoline. It is obvious that the methanol considerably affects the ID and CD period. This situation can be explained by several possible reasons. It is almost certain that the fuel properties are a result of these effects. There is a strong possibility that one of the most important reasons can be the higher LFS, heat evaporation and octane number of the methanol. These findings agree with the results of other studies. Previous studies have reported that the LFS substantially affects the combustion rate in the course of the early combustion phase, which is 0-10\% MFB [14]. Thus, the early combustion phase (CA0-10) is a crucial parameter for engine combustion quality due to flame development duration is considerably affected by the alcohol fuels [22]. CA10-90 duration can be identified by the flame propagation duration. This can be calculated by a period of the total fuel combustion duration that is equal to the $10-90 \%$ heat release rate period [21]. Besides, according to Zhang et al.
[18], reported that LFS increases with an increasing alcohol content so that $10-90 \%$ MFB and LFS has a strong relationship with each other.

Higher latent of the vaporization heat value of the alcohols lead to the cooling effect on the cylinder inside, which can a reduction in the combustion rate compared to gasoline. Therefore, the ID is considerably affected by the latent heat of vaporization and the vapor pressure [14]. Besides, the combustion stability can be improved by the higher octane number and charge cooling effect of the alcohols because of both parameters substantially affect the anti-knock ability [18].

However, the maximum cylinder pressure $\left(\mathrm{CP}_{\max }\right)$ and the maximum heat release rate values $\left(H_{R R} R_{\max }\right)$ are negatively affected by an increase in lambda values. For example, with increasing the lambda, the maximum cylinder pressure values obviously dropped from 41.63 to 38.87 bars at 0.8 to 1 lambda for gasoline. Furthermore, the maximum pressure dropped from 38.87 to 36.73 bars at 1 to 1.2 lambdas. On the other hand, the maximum heat release rate values dramatically decreased from 39.06 to $33.19 \mathrm{~J} /{ }^{\circ} \mathrm{CA}$ at 0.8 to 1 lambda for gasoline. Moreover, the maximum heat release rate 
considerably dropped from 33.19 to $25.75 \mathrm{~J} /{ }^{\circ} \mathrm{CA}$ at 1 to 1.2 lambdas. However, the M20 blend had an increase of $8.91 \%, 6.35 \%$, and $6.89 \%$ in the maximum cylinder pressure values at $0.8,1$, and 1.2 lambda values, respectively, compared to G100. In addition to this, the M20 blend had an increase of $1.56 \%, 3.98 \%$, and $8 \%$ in the maximum heat release rate values at $0.8,1$, and 1.2 lambda values, respectively, compared to G100. A possible explanation is that the excess air caused more lean combustion. Thus, $\mathrm{CP}_{\max }$ and $\mathrm{HRR}_{\max }$ values decreased with increasing lambda values. This finding is consistent with that of Ji and Wang [23] who reported that the cylinder temperature and fuel energy flow rate decreased with an increase of lambda values. Also, they determined that the increase of lambda values led to an extension in the ID and CD period. As can be seen in Table 5, the ID and $\mathrm{CD}$ periods prolonged with the increase of lambda values. On the other hand, the addition of methanol increased both of the $\mathrm{CP}_{\max }$ and $\mathrm{HRR}_{\max }$ values compared to gasoline, while decreased the ID period. For example, the M20 test fuel exhibited the highest the $\mathrm{CP}_{\max }$ and $\mathrm{HRR}_{\text {max }}$ values that were found to be 45.34 bars and $39.67 \mathrm{~J} /{ }^{\circ} \mathrm{CA}$ at 0.8 lambda, respectively. It could be that the addition of methanol led to more fuel introducing into the combustion chamber due to the increase of the BSFC values. Thus, the octane number of the blend was increased by the addition of methanol that increase also ignition resistance of the fuel blend [3]. In addition to this, the blend oxygen amount increased due to the high oxygen content of methanol which is approximately $50 \%$ oxygen in its mass [14]. Thus, more fuel accumulation in the combustion chamber in a short ID period had led to sudden and rapid combustion so that excess fuel caused an increase in the $\mathrm{CP}_{\max }$ and

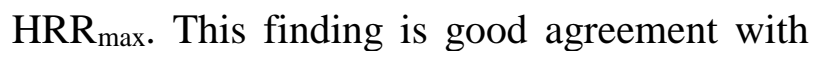
ref [6] result which is reported that the oxygen content increases the maximum HRR. Simultaneously high energy-released leads to relatively higher pressure in the short ID period [24]. This is because of the excess air needs more time for combustion. Interestingly, the CD of the M20 test fuel also exhibited an extension compared to gasoline all lambda values. However, the ID period decreased due to the higher LFS value of the methanol at lambda values [14]. The results, as shown in Fig. 3, indicate that the maximum BSFC value was reported to be $338.78 \mathrm{~g} / \mathrm{kWh}$ among the test fuels at $\lambda=0.8$.

Table 5 presents an overview value of ID, CD, $\mathrm{CP}_{\max }$, and $\mathrm{HRR}_{\max }$ which are very important parameters for combustion analysis of the test fuels. It can be seen in Table 5 that the results of the CD have an escalating trend with increased lambda values. This is because of the excess air needs more time for combustion. Interestingly, the CD of the M20 test fuel has also exhibited an extension compared to gasoline all lambda values. However, the ID period decreased due to the higher LFS value of the methanol [14]. This result can be explained by the fact that the higher the octane number, latent heat vaporization, and oxygen content of the methanol affected the combustion phases. These findings agree with the results of other studies that are reported a higher LFS [14,24], octane number [25], charge cooling effect [18], and extra oxygen content [26] of the alcohols considerably affect the combustion phasing compared to gasoline. In this respect, the minimum ID period was exhibited by the M20 test fuel at this engine condition. This situation can be explained by the high LFS of the methanol.

Table 5. The combustion characteristics of test fuels at various engine loads and lambda values

\begin{tabular}{cccccc}
\hline \multicolumn{5}{c}{$100 \%$ Engine Load } \\
\hline & $\begin{array}{c}\text { Lambda } \\
(\lambda)\end{array}$ & $\begin{array}{c}\mathrm{ID} \\
\left({ }^{\circ} \mathrm{CA}\right)\end{array}$ & $\begin{array}{c}\mathrm{CD} \\
\left({ }^{\circ} \mathrm{CA}\right)\end{array}$ & $\begin{array}{c}\mathrm{CP}_{\max } \\
(\mathrm{bar})\end{array}$ & $\begin{array}{c}\mathrm{HRR}_{\max } \\
\left(\mathrm{J} /{ }^{\circ} \mathrm{CA}\right)\end{array}$ \\
& 0.8 & 10.5 & 12 & 41.63 & 39.06 \\
$\mathrm{G} 100$ & 1 & 11.5 & 12.5 & 38.87 & 33.19 \\
& 1.2 & 16.5 & 15.5 & 36.73 & 25.75 \\
& 0.8 & 9 & 12.5 & 45.34 & 39.67 \\
$\mathrm{M} 20$ & 1 & 11 & 15 & 41.36 & 34.51 \\
& 1.2 & 13.5 & 17 & 39.26 & 27.81 \\
\hline
\end{tabular}

The crank angle values of the end of the combustion process that correspond to $90 \%$ of the MFB occurred to be at $372.5 \mathrm{CA}, 373 \mathrm{CA}$, and $374 \mathrm{CA}$ for the G100, 0.8, 1, and 1.2 lambda values respectively. In addition, it was obtained at $372.5 \mathrm{CA}, 374 \mathrm{CA}$, and $374 \mathrm{CA}$ for M20, respectively. It is obvious from these results that the end of the combustion process crank angle values have not considerably affected by the test fuels and lambda values. However, it can be concluded that the ID and CD parameters were subtantially affected by the methanol addition due to the methanol properties. 
Overall, it can be seen from the fuel properties of test fuels in Table 3 that the methanol specifications such as oxygen content, octane number, laminar flame speed, and latent heat vaporization values have very important effects on the ID, CD, $\mathrm{CP}_{\max }, \mathrm{HRR}_{\max }$ in the combustion period. Thus, the main characteristics of the combustion process were substantially affected by the methanol specifications such as oxygen content, octane number, laminar flame speed, and latent heat vaporization values. As Table 5 shows, there is a considerable difference between G100 and M20 test fuel combustion analysis results are highlighted.

\subsection{The exhaust emissions}

The exhaust emission characteristics such as $\mathrm{CO}, \mathrm{HC}, \mathrm{CO}_{2}$, and $\mathrm{NO}$ were given and also they have been deeply discussed according to the obtained results. These are provided insight into the analysis of the effects of lambda values and the addition methanol on the exhaust emissions. The variation of the $\mathrm{CO}$ emission values with regard to lambda values are as shown in Fig. 6. It is obvious in the figure that the $\mathrm{CO}$ emission dramatically decreased by an increase in the lambda values. This decreasing trend can be explained by the rich air-fuel mixture that can be led to an increase in the formation of $\mathrm{CO}$ emission due to incomplete combustion. This result is in agreement with the literature findings. For instance, Agarwal and Dhar [10] reported that insufficient oxygen availability caused an increase in $\mathrm{CO}$ emission due to incomplete combustion at higher engine load. Galloni et al. [19] presented a result that rich mixture has not fully oxidized to the formation of $\mathrm{CO}_{2}$ due to lack of enough $\mathrm{O}_{2}$. The formation of $\mathrm{CO}$ increased so that observed a reduction in engine thermal efficiency. Also, Ciniviz et al. [27] reported that insufficient oxygen as the major cause of $\mathrm{CO}$ emissions. The addition of methanol into gasoline considerably reduced the CO emission, except $\lambda=1.2$. Thus, the maximum reduction was observed that a decrease of $54.06 \%$ compared to the G100 at stoichiometric value $(\lambda=1)$. The lower $\mathrm{CO}$ emission formation due to the extra oxygen content of the alcohol blends was improved the combustion reaction. This result is in agreement with the literature findings $[10,28]$. However, the addition of methanol was exhibited by $4.35 \%$ an increase in the $\mathrm{CO}$ emission at $\lambda=1.2$. This situation can be explained by the fact that the lean air-fuel ratio leads to incomplete combustion due to lower flame speed. This result is supported by Pulkrabek [13] who noted that the leaner air-fuel ratio leads to a slower flame speed.

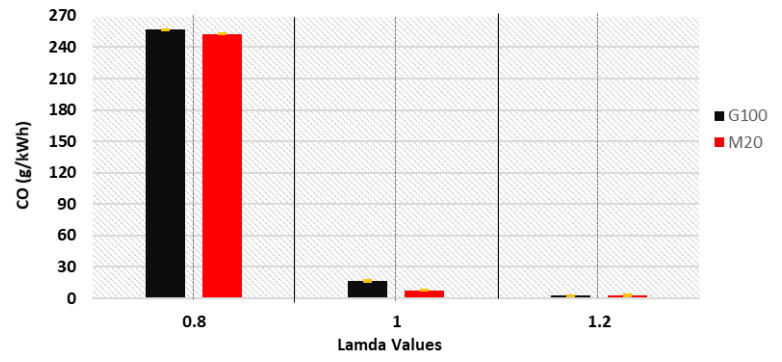

Figure 6. The variation of $\mathrm{CO}$ emission at different lambda values.

The changing of $\mathrm{HC}$ emission value according to the test fuels and lambda values are presented in Fig. 7. The emission values of $\mathrm{HC}$ were substantially decreased by an increase of lambda values. Moreover, the addition of methanol decreased the formation of $\mathrm{HC}$, except at $\lambda=0.8$. These reduction percentages of $\mathrm{HC}$ emission occurred as $0.94 \%$ and $8.51 \%$ with respect to gasoline at $\lambda=1$ and $\lambda=1.2$, respectively. In contrast to these, the addition of methanol had considerably an increase of $14.43 \%$ in the $\mathrm{HC}$ emissions compared to gasoline at $\lambda=0.8$. It seems possible that this situation is due to a lower combustion period and higher LFS of the methanol that negatively affected the formation of $\mathrm{HC}$ emissions. Besides, as can be seen in Fig. 3 that the highest BSFC value occurred at $\lambda=0.8$ lambda with M20 test fuel. In addition to this, a high evaporation heat value of the methanol can be withdrawn to heat from inside the cylinder. Thus, the charge cooling effect of the methanol may have caused an increase in the formation of $\mathrm{HC}$. This finding is supported by Yilmaz et al. [29] result. They reported that wall quenching effect and partial burns lead to an increase in HC emissions.

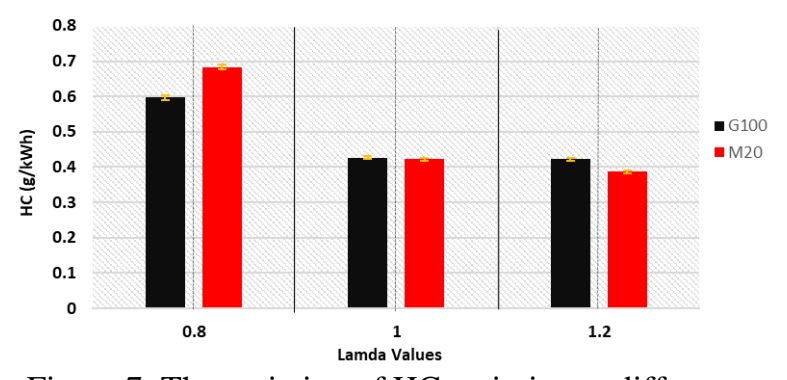

Figure 7. The variation of $\mathrm{HC}$ emission at different lambda values. 


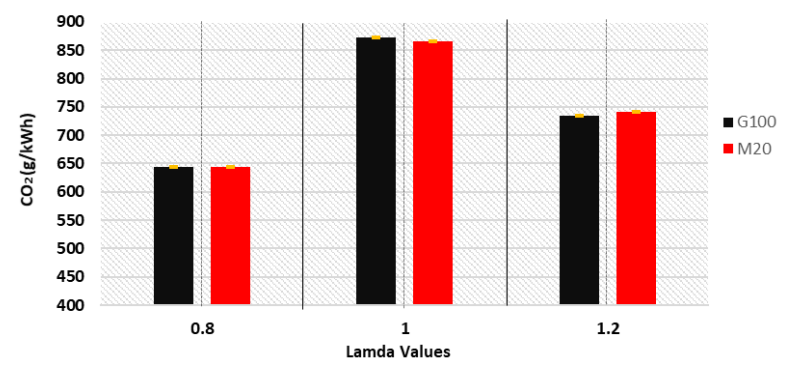

Figure 8. The variation of $\mathrm{CO}_{2}$ emission at different lambda values.

The variation of $\mathrm{CO}_{2}$ emission at different lambda values are given in Fig. 8. The emission values of $\mathrm{CO}_{2}$ in the exhaust gas are a good parameter for understanding the complete combustion in the cylinder [30]. The highest value of $\mathrm{CO}_{2}$ emission occurred at $\lambda=1$ for both test fuels. However, the lowest value of $\mathrm{CO}_{2}$ emission was obtained at $\lambda=0.8$. It is obvious from the results that the complete combustion occurred at $\lambda=1$. The aforementioned decreasing in the $\mathrm{CO}$ and $\mathrm{HC}$ values can be related to the increase of $\mathrm{CO}_{2}$ emissions because the complete combustion ensures a reduction in $\mathrm{CO}$ and $\mathrm{HC}$ emissions. These findings are in agreement with Sharudin et al. [31] study. They noted that the $\mathrm{CO}$ and $\mathrm{HC}$ emissions are decreased by all gasoline-methanol blends with iso-butanol additive due to the combustion efficiency is improved by the rich oxygen content of fuel blends. Therefore, an improvement is observed in the $\mathrm{CO}$ and $\mathrm{HC}$ emission value according to obtained results. In addition to this, Örs et al. [32] reported that the emissions of $\mathrm{CO}$ and $\mathrm{CO}_{2}$ have a rise and fall balance between each other. The addition of methanol slightly decreased by $0.87 \%$ of the $\mathrm{CO}_{2}$ emission at $\lambda=1$, while interestingly formation of $\mathrm{CO}_{2}$ was equal at $\lambda=0.8$ for both test fuels. However, the methanol had slightly an increase of $0.86 \%$ in the $\mathrm{CO}_{2}$ emission with compared to gasoline at $\lambda=1.2$. Considering the results of the $\mathrm{CO}_{2}$ emissions indicated that the $\mathrm{CO}_{2}$ emissions have not been substantially affected by the addition of methanol.

The variation of NO values for the test fuel at different lambda values are given in Fig. 9. $\mathrm{NO}_{\mathrm{x}}$ emissions substantially depend on the combustion parameters such as combustion temperature, combustion period, reaction speed, and oxygen content [33].

As can be seen from the figure that the value of NO increased with the rise of lambda values. It

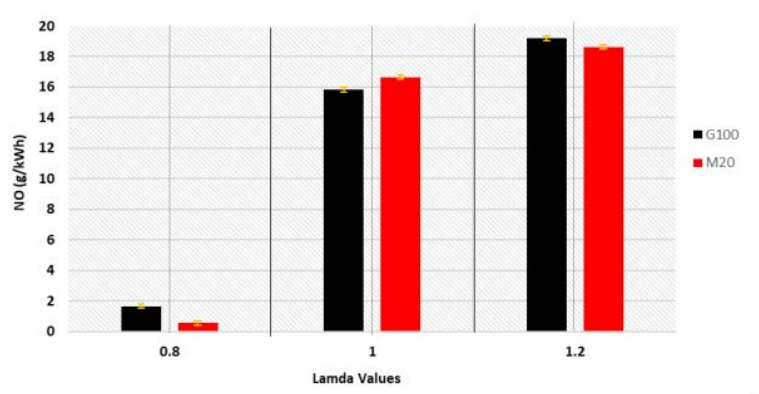

Figure 9. The variation of NO emission at different lambda values.

seems possible that this is due to the rich air-fuel ratio leads to the incomplete combustion. Thus, the value of NO emissions was dramatically lower than $\lambda=1$ and $\lambda=1.2$. This finding is also supported by the previous results in which presented in Fig. 6-7. In these figures, the values of $\mathrm{CO}$ and $\mathrm{HC}$ emissions substantially higher than others due to the incomplete combustion increased both of them. A strong relationship between the incomplete combustion and an increase of the $\mathrm{CO}$ and $\mathrm{HC}$ emission values have been reported in the literature [29,30]. Thus, it is almost certain that the lower NO emission values were a result of the inadequate air-fuel reaction at $\lambda=0.8$. In addition to this, it could be that the shortest combustion period as seen in Table 5 is a reason for the lower formation of $\mathrm{NO}$ emissions. On the other hand, the addition of methanol decreased the NO emissions that reduced by $67.2 \%$ and $2.91 \%$ with respect to gasoline at $\lambda=0.8$ and $\lambda=1.2$, respectively. This result may be explained by the good correlation between the characteristics of methanol and the formation of NO. In other words, the higher latent of heat evaporation of methanol decreased the combustion temperature due to the charge cooling effect. Besides, the higher LFS of methanol decreased the combustion duration period. Surprisingly, the value of NO increased by $5.11 \%$ compared to gasoline at $\lambda=1$. This inconsistency can be caused by a longer combustion period at the stoichiometric rate. Table 5 shows that there has been a gradual rise in the sum of the ID and CD periods to compare others. Namely, the addition of methanol was observed an increase in the combustion period by contrast with other lambda values. Thus, this increase in NO values could be due to a prolonged combustion period at $\lambda=1$. Comparing the test fuel results, it can be concluded that the addition of methanol led to a 
decrease the formation of NO at various lambda values, except at $\lambda=1$.

\section{Conclusion}

In this study, the engine performance, combustion process, and exhaust emission characteristics of a SI engine fueled by the methanol-gasoline (in vol. 20\% methanol) blends have been investigated in terms of various lambda values, a constant engine speed that is $2000 \mathrm{rpm}$, and at full engine load conditions. According to obtained results, some of the important conclusions can be drawn as below:

$>\quad$ The addition of methanol increased the thermal efficiency of the M20 fuel blend for all lambda values, except at $\lambda=1.2$. However, the highest efficiencies observed for both test fuels at $\lambda=1.2$.

$>\quad$ The highest BSFC values occurred at $\lambda=0.8$ due to the rich air-fuel mixture. The addition of methanol led to substantially an increase in the BSFC values with respect to gasoline at all of the lambda values due to the LHV of methanol.

$>\quad$ The BSFC values of the M20 fuel blend increased between $8.37 \%$ and $13.06 \%$ compared to gasoline. However, the thermal efficiency of the M20 increased due to some of the important properties of methanol such as the higher octane number, oxy-rich content, and LFS, except at $\lambda=1.2$. These properties ensure the proper working of the test engine without antiknocking or incomplete combustion.

$>\quad$ The ID and CD values increased with the increment of the lambda values. However, a decreasing trend observed for the $\mathrm{CP}_{\max }$ and $\mathrm{HRR}_{\max }$ at both test fuels.

$>\quad$ The addition of methanol decreased the ID period at all lambda values. However, it is not only increased the CD but also raised the $\mathrm{CP}_{\max }$ and $\mathrm{HRR}_{\max }$ values.

$>\quad$ The methanol specifications such as the oxygen content, octane number, the LFS, and latent heat vaporization values considerably affected to the some of the main characteristics of the combustion.

$>\quad$ Methanol has considerably effective in the formation of $\mathrm{CO}, \mathrm{HC}$, and $\mathrm{NO}$ emissions at full engine load.

The highest $\mathrm{CO}$ and $\mathrm{HC}$ emissions were occurred due to the inadequate combustion process at 0.8 lambda.

$>\quad$ The highest $\mathrm{CO}_{2}$ emissions were observed at $\lambda=1$ in consequence of the complete combustion process.

$>\quad$ The lowest $\mathrm{NO}$ emission values were observed at $\lambda=0.8$. Because the shorter combustion period and the rich air-fuel mixture have not caused the formation of NO.

The LFS, oxygen content, latent heat vaporization, octane number, and lower heating value properties have considerably affected the engine performance, combustion process, and exhaust emission characteristics.

This study presents that the addition of methanol to gasoline and various lambda values substantially influence on the engine performance, combustion process, and exhaust emissions. The results of this study are explained that the effects of methanol properties such as the oxygen content, octane number, LFS, and latent heat vaporization, and also the variations of air-fuel ratio effects. These findings are extended our knowledge of the usage of methanol effects with the various lambda values on performance, combustion, and emissions in a SI engine. Further research is recommended that investigates the effects of the different alcohols, hydrogen, and natural gas, or biogas, etc. alternative fuels gas on the engine performance, combustion, and emissions at various lambda values.

\section{Acknowledgment}

This work has been supported by Amasya University. Also, I would like to thank the Erciyes University for laboratory facilities and other support.

\section{Nomenclature}

$\begin{array}{ll}\mathrm{BSFC} & \begin{array}{l}\text { Brake specific fuel consumption } \\ (\mathrm{g} / \mathrm{kWh})\end{array} \\ \mathrm{CA} & \begin{array}{l}\text { Crank angle (Degree) } \\ \text { Combustion duration } \quad \text { (Crank }\end{array} \\ \mathrm{CD} & \begin{array}{l}\text { Angle) } \\ \mathrm{CO}\end{array} \\ \mathrm{CO}_{2} & \text { Carbon monoxide } \\ \mathrm{CP}_{\max } & \text { The maximum cylinder pressure } \\ \mathrm{ECU} & \text { (bar) } \\ \mathrm{G} 100 & \text { Engine control unit } \\ \mathrm{ID} & \text { Ignition delay (Crank Angle) } \\ \mathrm{HRR}_{\max } & \text { The max. heat release rate (J/CA) }\end{array}$




$\begin{array}{ll}\text { LHV } & \text { Lower heating value }(\mathrm{MJ} / \mathrm{kg}) \\ \text { LFS } & \text { Laminar flame speed }(\mathrm{cm} / \mathrm{s}) \\ \text { MFB } & \text { Mass fraction burned } \\ & \text { G80\% Gasoline }+20 \% \text { Methanol (in } \\ \text { M20 } & \text { vol.) } \\ \mathrm{NO} & \text { Nitric oxide } \\ \mathrm{O}_{2} & \text { Oxygen } \\ \mathrm{SI} & \text { Spark Ignition } \\ \lambda & \text { Lambda }\end{array}$

\section{References}

1. Demirbas, A., "Biofuels sources, biofuel policy, biofuel economy and global biofuel projections" Energy Conversion and Management, 49, 8,2106-2116.2008.

2. Demirbas, A., "Biofuels securing the planet's future energy needs" Energy Conversion and Management, 50, 9,22392249.2009.

3. Sarıkoç, S., Fuels of the Diesel-Gasoline Engines and Their Properties, in Diesel and Gasoline Engines, R. Viskup, Editor. 2020, IntechOpen: Chapter-2, London,. p. 1-17.

4. Sarıkoç, S., Bioenergy Potential of Turkey's Forest Sources, Biomass Energy Conversion Methods, Products, and Applications, in Renewable Energy [Working Title], T. Taner, Editor. 2020, IntechOpen: London. p. 1-22.

5. Danaiah, P., P.R. Kumar, and D.V. Kumar, "Effect of methanol gasoline blended fuels on the performance and emissions of SI engine" International Journal of Ambient Energy, 34, 4, 175-180.2013.

6. Örs, İ., "Experimental investigation of the cetane improver and bioethanol addition for the use of waste cooking oil biodiesel as an alternative fuel in diesel engines" Journal of the Brazilian Society of Mechanical Sciences and Engineering, 42, 42020.

7. Örs, İ., A. Kahraman, and M. Ciniviz, "Performance, emission and combustion analysis of a compression ignition engine using biofuel blends" Thermal Science, 21, 1 Part B,511-522.2017.

8. Balki, M.K. and C. Sayin, "The effect of compression ratio on the performance, emissions and combustion of an SI (spark ignition) engine fueled with pure ethanol, methanol and unleaded gasoline" Energy, 71,194-201.2014.

9. Selçuk Sarıkoç, Sebahattin Ünalan, and
M.İ. İlhak, "An Experimental Investigation Of The Gasoline-Methanol Fuel Blend Effects On The Engine", in 5th International Conference on Advances in Mechanical Engineering 17-19 December 2019: İstanbul, 2019.

10. Agarwal, A.K., H. Karare, and A. Dhar, "Combustion, performance, emissions and particulate characterization of a methanolgasoline blend (gasohol) fuelled medium duty spark ignition transportation engine" Fuel Processing Technology, 121,16-24.2014.

11. Yilmaz, İ. and M. Taştan, "Investigation of hydrogen addition to methanol-gasoline blends in an SI engine" International Journal of Hydrogen Energy, 43, 44,20252-20261.2018.

12. Akif Ceviz, M., A.K. Sen, A.K. Küleri, and İ. Volkan Öner, "Engine performance, exhaust emissions, and cyclic variations in a lean-burn SI engine fueled by gasolinehydrogen blends" Applied Thermal Engineering, 36,314-324.2012.

13. Pulkrabek, W.W., "Engineering Fundamentals of the Internal Combustion Engine", Prenrice Hall, 1997.

14. Li, Y., J. Gong, Y. Deng, W. Yuan, J. Fu, and B. Zhang, "Experimental comparative study on combustion, performance and emissions characteristics of methanol, ethanol and butanol in a spark ignition engine" Applied Thermal Engineering, 115,53-63.2017.

15. Holman, J.P., "Experimental methods for engineers/ J.P. Holman. 8th edition", Raghothaman Srinivasan, 2012.

16. Ileri, E., "Experimental study of 2ethylhexyl nitrate effects on engine performance and exhaust emissions of a diesel engine fueled with n-butanol or 1-pentanol diesel-sunflower oil blends" Energy Conversion and Management, 118,320-330.2016.

17. Duan, X., Y. Li, J. Liu, G. Guo, J. Fu, Q. Zhang, S. Zhang, and W. Liu, "Experimental study the effects of various compression ratios and spark timing on performance and emission of a lean-burn heavy-duty spark ignition engine fueled with methane gas and hydrogen blends" Energy, 169,558-571.2019.

18. Zhang, Z., T. Wang, M. Jia, Q. Wei, X. Meng, and G. Shu, "Combustion and particle number emissions of a direct injection spark ignition engine operating on ethanol/gasoline and n-butanol/gasoline blends with exhaust gas recirculation" Fuel, 130,177-188.2014. 
19. Galloni, E., G. Fontana, S. Staccone, and F. Scala, "Performance analyses of a sparkignition engine firing with gasoline-butanol blends at partial load operation" Energy Conversion and Management, 110,319326.2016.

20. Çelik, M.B., B. Özdalyan, and F. Alkan, "The use of pure methanol as fuel at high compression ratio in a single cylinder gasoline engine" Fuel, 90, 4,1591-1598.2011.

21. Solmaz, H., "Combustion, performance and emission characteristics of fusel oil in a spark ignition engine" Fuel Processing Technology, 133,20-28.2015.

22. Zhang, B., C. Ji, and S. Wang, "Investigation on the lean combustion performance of a hydrogen-enriched n-butanol engine" Energy Conversion and Management, 136,36-43.2017.

23. Ji, C. and S. Wang, "Effect of hydrogen addition on lean burn performance of a sparkignited gasoline engine at 800rpm and low loads" Fuel, 90, 3,1301-1304.2011.

24. Li, Y., L. Meng, K. Nithyanandan, T.H. Lee, Y. Lin, C.-f.F. Lee, and S. Liao, "Combustion, performance and emissions characteristics of a spark-ignition engine fueled with isopropanol- $\mathrm{n}$-butanol-ethanol and gasoline blends" Fuel, 184,864-872.2016.

25. Amirabedi, M., S. Jafarmadar, and S. Khalilarya, "Experimental investigation the effect of $\mathrm{Mn} 2 \mathrm{O} 3$ nanoparticle on the performance and emission of SI gasoline fueled with mixture of ethanol and gasoline" Applied Thermal Engineering, 149,512-519.2019.

26. Canakci, M., A.N. Ozsezen, E. Alptekin, and M. Eyidogan, "Impact of alcohol-gasoline fuel blends on the exhaust emission of an SI engine" Renewable Energy, 52,111-117.2013.

27. Kahraman, A., Ciniviz, M., Ors, I., Oguz, H., "The Effect on Performance and Exhaust Emissions of Adding Cotton Oil Methyl Ester to Diesel Fuel " International Journal of Automotive Engineering and Technologies 5, 4,148-154.2016.

28. Raviteja, S. and G.N. Kumar, "Effect of hydrogen addition on the performance and emission parameters of an SI engine fueled with butanol blends at stoichiometric conditions" International Journal of Hydrogen Energy, 40, 30,9563-9569.2015.

29. Yilmaz, N., A. Atmanli, and F.M. Vigil,
"Quaternary blends of diesel, biodiesel, higher alcohols and vegetable oil in a compression ignition engine" Fuel, 212,462-469.2018.

30. Yesilyurt, M.K., M. Aydin, Z. Yilbasi, and M. Arslan, "Investigation on the structural effects of the addition of alcohols having various chain lengths into the vegetable oilbiodiesel-diesel fuel blends: An attempt for improving the performance, combustion, and exhaust emission characteristics of a compression ignition engine" Fuel, 269,117455.2020.

31. Sharudin, H., N.R. Abdullah, G. Najafi, R. Mamat, and H.H. Masjuki, "Investigation of the effects of iso-butanol additives on spark ignition engine fuelled with methanol-gasoline blends" Applied Thermal Engineering, 114,593600.2017.

32. Örs, İ., Sarıkoç, Selçuk, Atabani, A. E., Ünalan, Sebahattin, "Experimental investigation of effects on performance, emissions and combustion parameters of biodiesel-dieselbutanol blends in a direct-injection CI engine" Biofuels, 11, 2,121-134.2020.

33. Barrios, C.C., A. Domínguez-Sáez, and D. Hormigo, "Influence of hydrogen addition on combustion characteristics and particle number and size distribution emissions of a TDI diesel engine" Fuel, 199,162-168.2017. 